\title{
Extracorporeal membrane oxygenation support during the coronavirus disease 2019 pandemic: Outcomes and technical considerations
}

Omar Saeed, MD, MS, ${ }^{\mathrm{a}}$ and Scott Silvestry, $\mathrm{MD}^{\mathrm{b}}$

Over the course of 18 months, global spread of coronavirus disease 2019 (COVID-19) has led to nearly 4 million deaths. ${ }^{1}$ Severe acute respiratory syndrome coronavirus 2 (the novel coronavirus identified as the cause of COVID19) targets the respiratory system and mortality during COVID-19 is related to the development of acute respiratory distress syndrome, accompanied by a severe cytokine storm, with subsequent cardiopulmonary collapse. ${ }^{2,3}$ Early in the pandemic, it was noted that the utility of mechanical ventilation was limited in cases of severe respiratory failure with reports of nearly $90 \%$ mortality $^{4}$ and the role of extracorporeal membrane oxygenation (ECMO) was questionable. Although initial reports showed poor outcomes with ECMO during COVID-19, expert consensus supported its use in selected patients. ${ }^{5}$ A year and half into the pandemic, ECMO continues to be employed not so uncommonly, with more than 8000 cases noted in the Extracorporeal Life Support Organization (ELSO) registry. ${ }^{6}$ Observational studies indicate that ECMO can be a viable method of mechanical support with refractory respiratory failure from COVID19. .10 $^{-10}$ Addressing key domains such as standardizing cannulation criteria and technical considerations surrounding circuit deployment, cannulation strategies, patient selection, and management from experiences thus far during the pandemic can further improve outcomes of this lifesaving modality (Figure 1).

\footnotetext{
From the ${ }^{a}$ Division of Cardiology, Montefiore Medical Center, Albert Einstein College of Medicine, Bronx, NY; and ${ }^{\mathrm{b}}$ Division of Cardiothoracic Surgery, Advent Health Transplant Institute, Advent Health, Orlando, Fla.

Dr Saeed is supported by the National Institutes of Health/National Heart, Lung, and Blood Institute (grant No. K23HL145140).

Received for publication July 27, 2021; accepted for publication Sept 15, 2021; available ahead of print Oct 4, 2021.

Address for reprints: Omar Saeed, MD, MS, Division of Cardiology, Montefiore Medical Center, Albert Einstein College of Medicine, 3400 Bainbridge Ave, Bronx, NY 10467 (E-mail: osaeed@montefiore.org); or Scott Silvestry, MD, Advent Health Transplant Institute, Advent Health Orlando, 2415 North Orange Ave, Suite 600, Orlando, FL 32804 (E-mail: Scott.Silvestry.MD@ AdventHealth.com).

JTCVS Open 2021;8:77-82

2666-2736

Copyright (c) 2021 The Author(s). Published by Elsevier Inc. on behalf of The American Association for Thoracic Surgery. This is an open access article under the CC BY-NC-ND license (http://creativecommons.org/licenses/by-nc-nd/4.0/).

https://doi.org/10.1016/j.xjon.2021.09.022
}

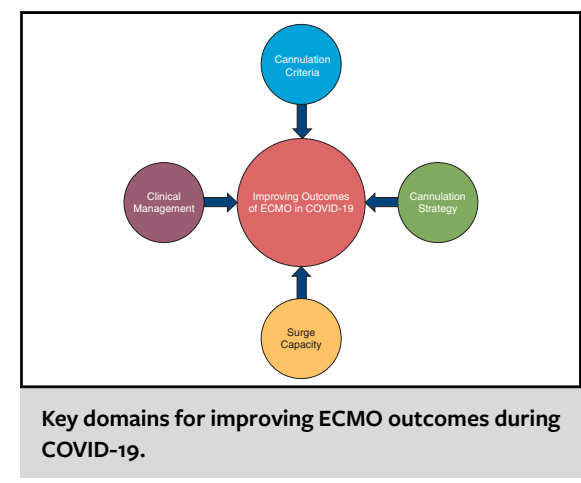

CENTRAL MESSAGE

ECMO has served as an essential and lifesaving modality in appropriately selected patients with severe respiratory failure from COVID-19.

See Commentary on page 83 .

\section{EARLY EXPERIENCES AND GUIDELINES}

During March 2020, the first case series of 12 patients with severe COVID-19 placed on ECMO was reported from Wuhan, China. ${ }^{5}$ In that brief report, poor outcomes were noted with 5 deaths and an additional 4 patients experiencing poor neurologic outcomes. A pooled analysis of 4 centers from surrounding regions with patients supported by ECMO yielded similarly unpromising outcomes with no differences in comparison to conventional therapy (odds ratio, 2.0; 95\% confidence interval [CI], 0.49-8.16; $P=.99) .{ }^{11}$ These preliminary and small reports portended a gloomy and potentially very limited role for ECMO in patients with COVID-19.

Notwithstanding unpromising early results, initial guidance for ECMO use during COVID-19 was provided by ELSO. ${ }^{12}$ That document underscored use of antecedent measures such as prone positioning, neuromuscular blockade, and high-positive end-expiratory pressure for patients with severe hypoxia defined by a ratio of arterial oxygen tension $\left(\mathrm{PaO}_{2}\right)$ to inspired oxygen fraction $\left(\mathrm{FIO}_{2}\right)$ $<150 \mathrm{~mm} \mathrm{Hg}$. In those with progressive hypoxia $\left(\mathrm{PaO}_{2}\right.$ :$\mathrm{FiO}_{2}<80 \mathrm{~mm} \mathrm{Hg}$ for 6 hours or $<50 \mathrm{~mm} \mathrm{Hg}$ for 3 hours) or acidosis ( $\mathrm{pH}<7.25$ with hypercapnia; ie, arterial carbon 


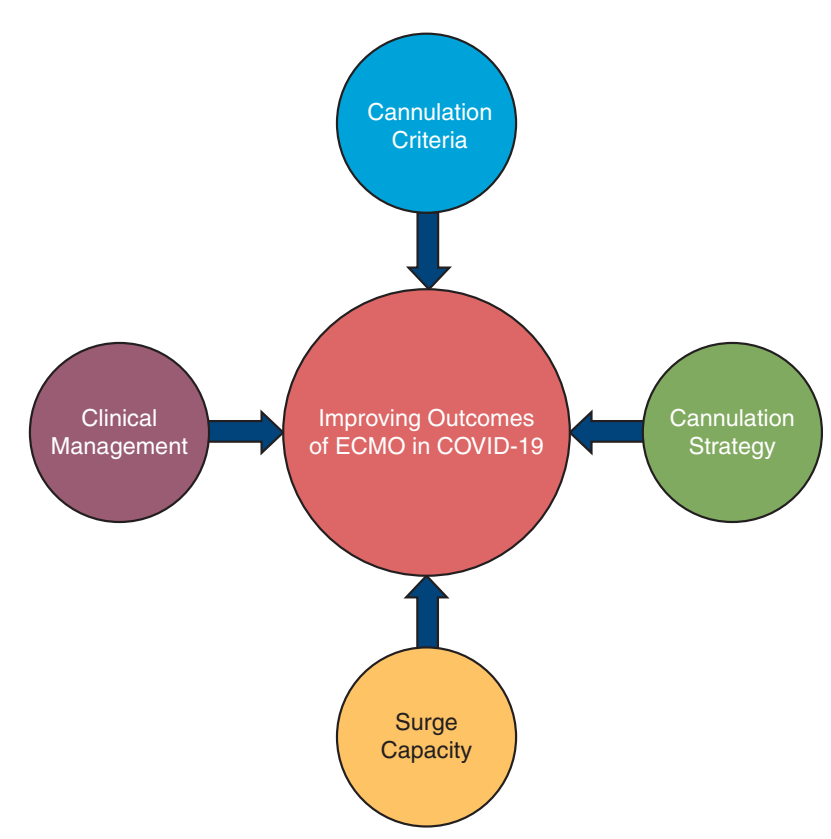

FIGURE 1. Key domains for improving extracorporeal membrane oxygenation $(E C M O)$ outcomes during coronavirus disease 2019 (COVID-19).

dioxide tension $\geq 60 \mathrm{~mm} \mathrm{Hg}$ for 6 hours) without contraindications, ECMO was recommended. ECMO was also recommended for patients with hypoventilation and acidosis ( $\mathrm{pH}<7.25$, arterial carbon dioxide tension $\geq 60 \mathrm{~mm} \mathrm{Hg}$ for 6 hours) in the absence of severe hypoxia $\left(\mathrm{PaO}_{2}: \mathrm{FIO}_{2}\right.$ $\geq 150 \mathrm{~mm} \mathrm{Hg}) .{ }^{12}$ With these guidelines and an exponentially rising burden of cases, ECMO was commonly employed in North America and Europe.

\section{PATIENT CHARACTERISTICS AND OUTCOMES WITH ECMO DURING COVID-19}

Several studies from around the world with at least 200 cases have reported in-hospital mortality ranging from $37 \%$ to $54 \%$ (Figure 2). During September 2020, clinical outcomes from the global ELSO registry were reported. ${ }^{7}$ This largest-to-date, observational analysis comprised 1035 patients from 213 hospitals across 36 countries placed on ECMO between January 16 and May 1, 2020. In this cohort, patients had a mean age of 49 years (range, 4157 years), 47\% were obese with a body mass index $>30$, and only $30 \%$ were free of comorbidities. Prone positioning and neuromuscular blockade were used in majority of patients before ECMO placement and pre-ECMO $\mathrm{PaO}_{2}: \mathrm{FIO}_{2}$ was $72 \mathrm{~mm} \mathrm{Hg}$ (range, 59-94 mm Hg). Overall, 90-day in-hospital mortality was noted to be $37.4 \%$ (95\% confidence interval, $34.4 \%-40.4 \%$ ) with $30 \%$ of the patients being discharged home or to an acute rehabilitation center. Tracheostomy was performed in 444 patients. In multivariable analysis, advanced age, immune-compromised status,

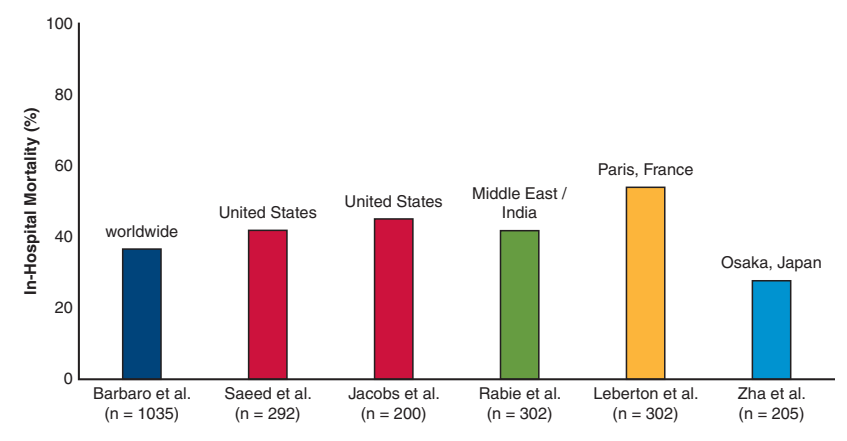

FIGURE 2. In-hospital mortality during extracorporeal membrane oxygenation for coronavirus disease 2019 in studies with at least 200 cases.

chronic respiratory disease, lower $\mathrm{PaO}_{2}: \mathrm{FIO}_{2}$ ratio, preECMO cardiac arrest, and renal injury were noted to be associated with death.

To gain additional insight into ECMO characteristics and outcomes within the United States, we formed and reported results from the COVID-19 ECMO Working Group. ${ }^{8}$ During the study period from March 1 to September 30, 2020, 292 patients were supported by ECMO across 17 participating centers. ${ }^{8}$ Similar to the worldwide ELSO report, patients had a mean age of 49 years (range, 3957 years), 38\% did not have comorbidities, and preECMO $\mathrm{PaO}_{2}: \mathrm{FIO}_{2}$ was $77 \mathrm{~mm} \mathrm{Hg}$ (range, 63-101 mm Hg). More than half $(56 \%)$ were transferred from another hospital. Biomarkers of inflammation and coagulation were highly elevated before ECMO placement (C-reactive protein, $21 \mathrm{mg} / \mathrm{dL}$ [range, $9-45 \mathrm{mg} / \mathrm{dL}$ ], ferritin, $1187 \mathrm{ng} / \mathrm{mL}$ [range, 683-1095 $\mathrm{ng} / \mathrm{mL}$ ], and D-dimer $8.6 \mu \mathrm{g} / \mathrm{mL}$ [range, 2.6$963 \mu \mathrm{g} / \mathrm{mL}])$. In this cohort, $280(96 \%)$ of the patients were placed on venovenous (VV)-ECMO and $66 \%$ of the cannulations were performed at the bedside or in an intensive care unit procedure room. Heparin was used in $71 \%$ of the patients for anticoagulation, followed by argatroban and bivalirudin. Bleeding requiring transfusion $(74 \%)$, renal failure requiring replacement therapy $(46 \%)$, and secondary infections $(55 \%)$ were commonly observed adverse events. Overall, 90-day in-hospital mortality was $42 \%$ ( $95 \%$ confidence interval, 36\%-47\%), which persisted after exclusion of patients in overlapping centers from the ELSO report. The most common cause of death was multiorgan failure and stroke occurred in $10 \%$ of the cases. In a key observation, it was noted that patients who died were placed on ECMO nearly 4 days later in comparison to those that were eventually discharged or transferred alive. Thus, close monitoring of tenuous mechanically ventilated patients for early ECMO placement within 48 to 72 hours after presentation has an essential role in improving outcomes. ${ }^{8}$

A centralized ECMO referral network was formed by a group of 17 hospitals in the Ile-de-France (Greater Paris) region. This group carried out a 4-step process to prepare inventory, standardize workflow and ECMO criteria, form a 
centralized communications hub with daily e-mailed reports, and conduct weekly meetings and sharing of information with local and international groups. ECMO criteria were similar to those proposed by the ELSO guidance document and the ECMO to Rescue Lung Injury in Severe ARDS trial, ${ }^{13}$ with exclusion of patients older than age 70 years, presence of serious comorbidities, cardiac arrest, refractory multiorgan failure or Simplified Acute Physiology Score-II $>90$, irreversible neurologic injury, or ongoing ventilation beyond 10 days. This group dispatched a mobile team composed of a cardiovascular surgeon and a perfusionist to a patient's bedside for cannulation with verification by ultrasonography and chest radiograph. Results are reported from a group of 302 patients placed on ECMO from March 8 to June 3, 2020. Patients had a mean age of 52 years (range, $45-58$ years), $78 \%$ were men with a pre-ECMO $\mathrm{PaO}_{2}: \mathrm{FIO}_{2}$ of $61 \mathrm{~mm} \mathrm{Hg}$ (range, $54-70 \mathrm{~mm} \mathrm{Hg}$ ). Prone positioning and neuromuscular blockage were utilized in more than $90 \%$ of patients. Overall, the 90-day in-hospital mortality was $46 \%$. Center experience, evident by hospitals managing at least $30 \mathrm{VV}$ ECMO cases in the prior year, was noted to be independently associated with improved survival. ${ }^{9}$ Additional collaborative reports have also been reported from Southern California, the Middle East, India, and Japan showing similar outcomes with rapid deployment of mobile units ${ }^{14}$ and establishment of new centers under expert guidance. $^{10,15}$

Numerous additional observational studies from around the world have also reported ECMO outcomes during COVID-19. ${ }^{10,16-21}$ A recent meta-analysis of 22 reports with 1896 cases from December 1, 2019, to January 10, 2021 , showed a pooled in-hospital mortality of $37.1 \%$ $(95 \%$ CI, $32.3 \%-42.0 \%))^{22}$ In that pooled analysis, the average ECMO support time was 15.1 days, increasing age was associated with poorer survival, and renal complications were commonly reported during device support. ${ }^{22}$

In complement to the studies mentioned above, estimates pertaining to the effectiveness of ECMO during COVID-19 with comparative groups have also been reported. The Study of the Treatment and Outcomes in Critically Ill Patients With COVID-19 investigators utilized a multicenter cohort of 68 centers in the United States to compare survival in patients with severe hypoxic respiratory failure from COVID-19 who were and were not initiated on ECMO during the first 7 days of admission to an intensive care unit. The study design emulated a clinical trial with intensive care unit time matching and after adjustment for covariates, those patients receiving ECMO had lower mortality (hazard ratio, 0.55; 95\% CI, 0.41-0.74). ECMO remained associated with better survival across subgroups of progressive baseline hypoxia. ${ }^{23}$ The Lille Intensive Care COVID-19 group from France compared the outcomes with ECMO use between patients with acute respiratory distress syndrome from COVID-19 versus historical controls with influenza. Patients with COVID-19 had a lower Simplified Acute Physiology Score-II score (58 [range, 37-64] vs 68 [range, 26-34]; $P=.039$ ) and were cannulated later at 6 versus 3 days $(P=.004)$. Despite these differences, patients with COVID-19 and influenza had similar 28-day mortality $(43.3 \%$ vs $50 \%[P=.63]){ }^{24}$

Given the weight of the observations provided by the studies mentioned above, ECMO appears to be a suitable platform in appropriately selected patients. However, because nearly half of the patients may not survive despite ECMO support, judicious use of this supportive and highly resource-intensive modality is critical. To further assist with patient selection, ELSO released an updated consensus document with recommended indications and contraindications in adult patients. Advanced age, significantly frailty, prolonged ventilation (ie, >10 days), overt baseline comorbidities with end organ dysfunction, severe multiorgan failure, uncontrolled bleeding, inability to take blood products or anticoagulation therapy, and ongoing cardiopulmonary resuscitation remain important absolute contraindications to ECMO. ${ }^{25}$ Relative contraindications such as use in patients older than age 65 years and in those with a body mass index $\geq 40$ may require additional study and caseby-case discussions.

\section{TECHNICAL CONSIDERATIONS}

COVID-19 presents a unique set of conditions for ECMO use related to the highly contagious nature of the virion, surge potential, prolonged support times, a hyperinflammatory state, ${ }^{26}$ and possibility for mixed cardiopulmonary failure. Given these challenges, certain key technical aspects pertaining to cannulation, circuit deployment, and management are highlighted below.

\section{Cannulation Strategies}

A simple method of cannulation proposed early in the pandemic was through the right internal jugular and femoral veins (Figure 3, A). Because this type of cannulation can be accomplished with minimal imaging and personnel and provide high flows with limited mixing in the right atrium, it was indeed the most applied method. Ninety percent of the patients were cannulated through the femorojugular approach in the Parisian experience and nearly half $(47 \%)$ in the US-based ECMO COVID-19 Working Group cohort were supported in this manner. ${ }^{8,9}$

To avoid 2 separate sites of cannulation and evade femoral involvement to promote mobility, cannulation can also be performed through a single dual-lumen cannula. At Montefiore Medical Center, we used the single, duallumen cannula (Medtronic Inc, Minneapolis, Minn) (Figure 3, B), which was placed at the bedside using ultrasound guidance with the distal tip positioned into the inferior vena cava. Use of the Protek Duo TandemHeart 

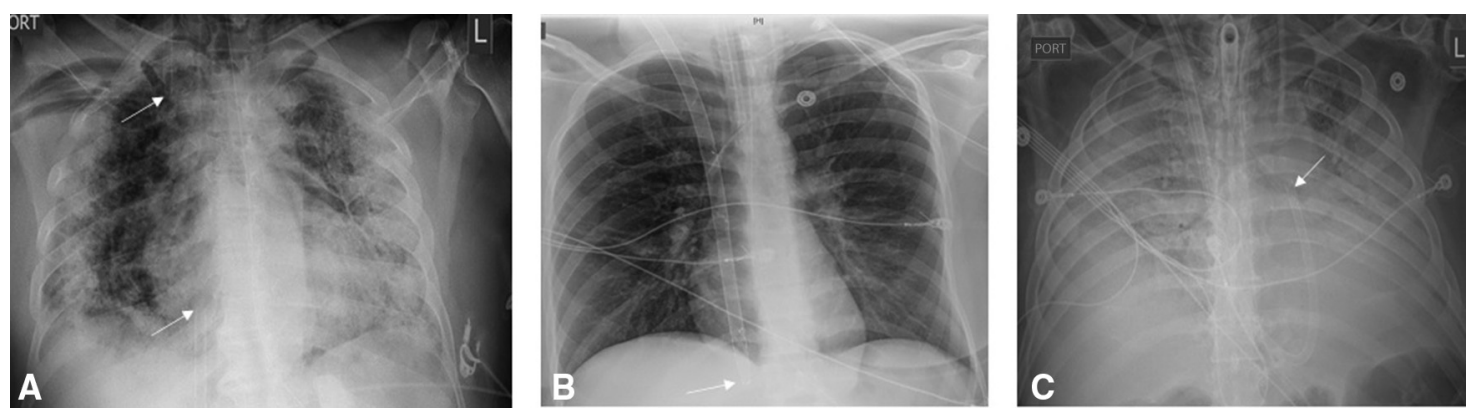

FIGURE 3. Chest radiographs of patients with severe coronavirus disease 2019 pneumonia on venovenous extracorporeal membrane oxygenation through cannulas in the right femoral and right jugular veins (A), a single, dual-lumen cannula with tip positioned in the inferior vena cava and right atrial junction (B), and a single, dual-lumen cannula with tip positioned in the main pulmonary artery (C). Arrows indicate cannula tip.

cannula (CardiacAssist Inc, Pittsburgh, Pa) was reported by the group from Advocate Christ Medical Center and Rush University Medical Center in Chicago, Ill (Figure 3,C). ${ }^{16}$ In the operating room, the right internal jugular vein was accessed and the distal tip of the cannula was placed in the main pulmonary artery under fluoroscopic and echocardiographic guidance. In their initial experience with 40 patients, this group reported a highly promising survival to discharge of $73 \% .{ }^{16}$ Superiority of neck-only cannulation is plausible because it increases mobility and directed flow into the pulmonary artery allows for right ventricle support. However, these advantages are balanced by the simplicity of the 2-cannula femorofemoral or femorojugular approach. Further studies are needed to compare the outcomes and complications of dual, single, and directed cannulation methods.

\section{Circuit Deployment}

At Advent Health Orlando, an intensive care unit procedure room was established with standardization of cannulation strategy, equipment, and personnel (Figure 4). Using the femorojugular approach, the surgeon and surgical assistant were able cannulate within 5 to 7 minutes, leading to swift establishment of ECMO support. There was rapid availability of anesthesia staff, and imaging modalities such as fluoroscopy and transesophageal echocardiography were accessible within the room. Due to standardization, supplies and personal protective equipment were easily

COVID-19 ECMO Cannulation Room
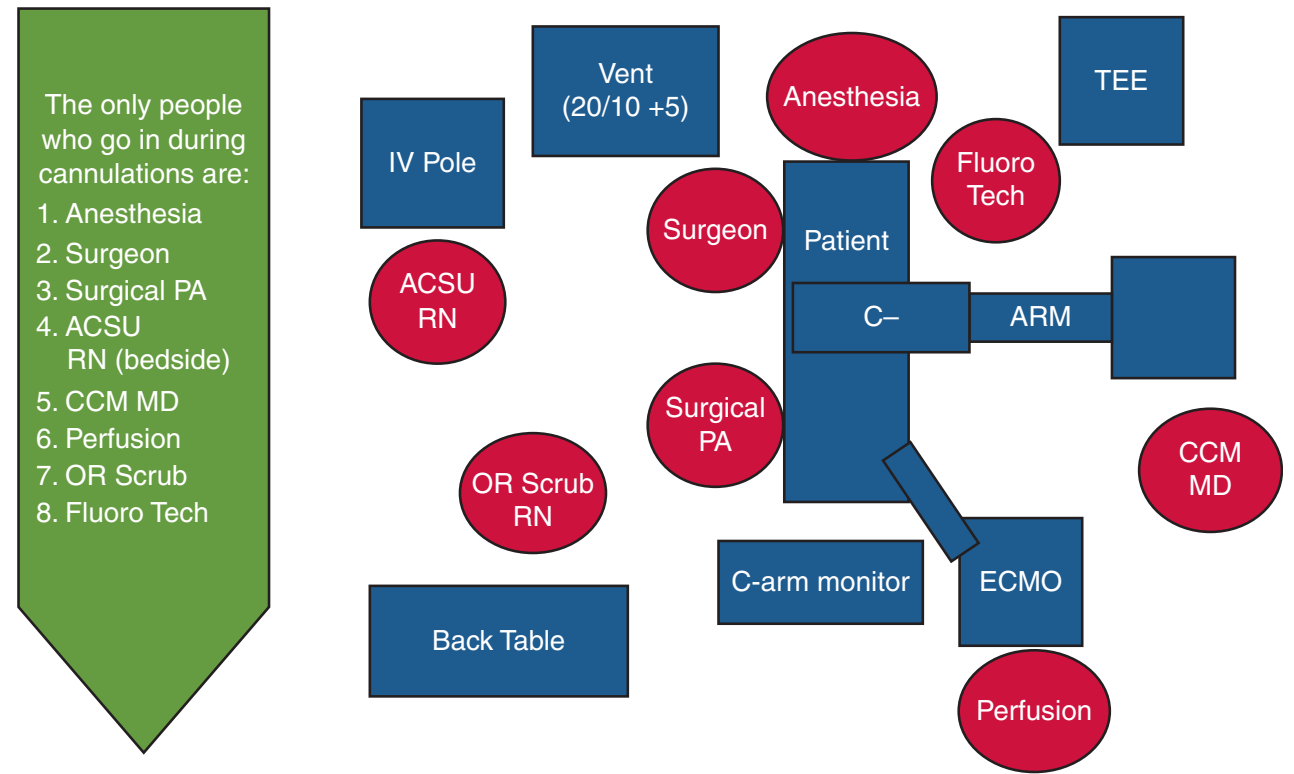

FIGURE 4. Schematic of coronavirus disease 2019 (COVID-19) extracorporeal membrane oxygenation support (ECMO) cannulation room at the Advent Health Transplant Institute in Orlando, Fla. Vent, Ventilator; TEE, transesophageal echocardiography; $I V$, intravenous; $P A$, physician assistant; $A C S U$, acute care surgical unit; $R N$, registered nurse; $A R M$, C-shaped arm; $C C M$, critical care unit; $M D$, physician/surgeon; OR, operating room; Fluoro Tech, fluoroscopy technician. 
TABLE 1. Recommendations for extracorporeal membrane oxygenation (ECMO) placement, management, and operations during the coronavirus 2019 (COVID-19) pandemic

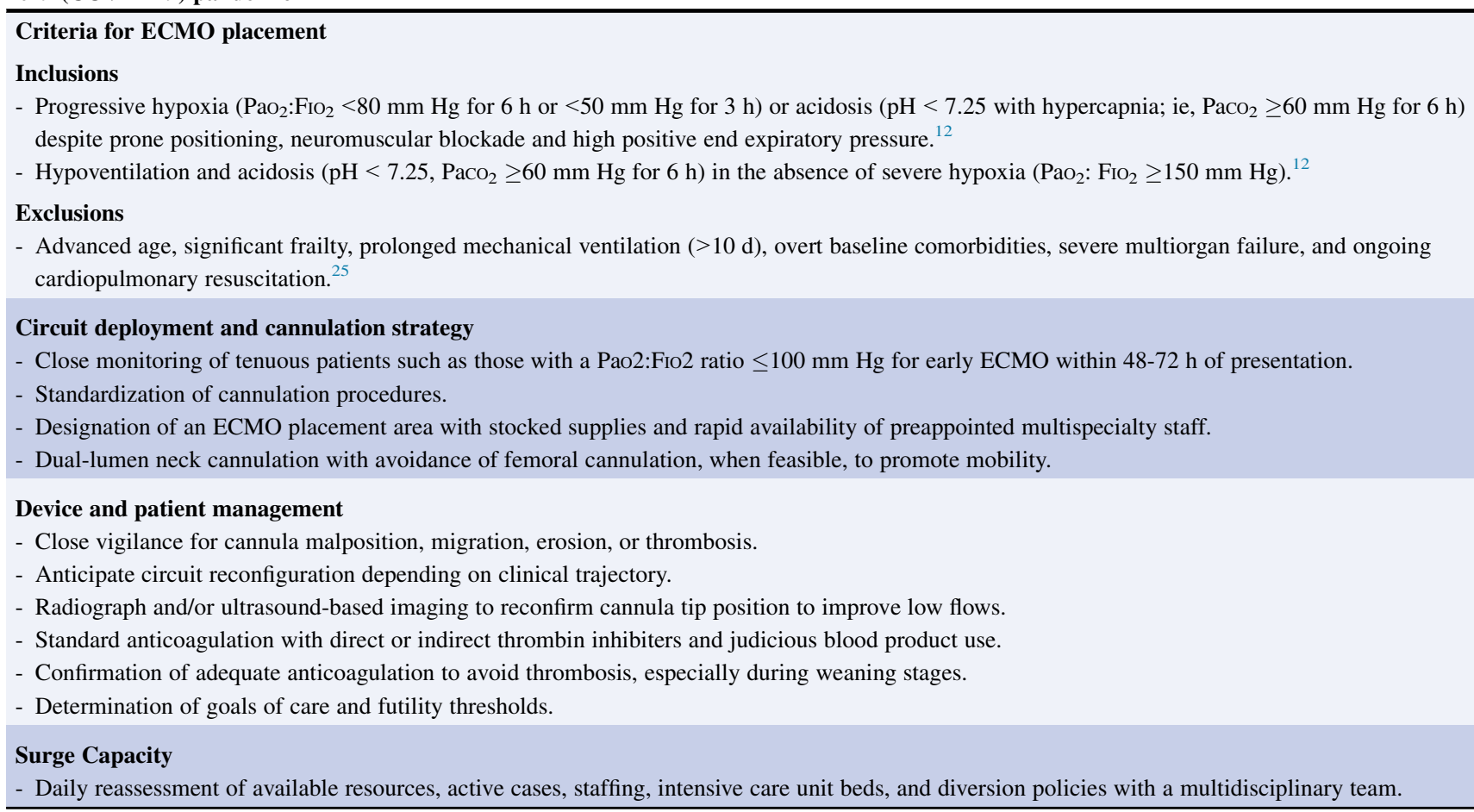

accessible and complications such as a bradycardia or hypoxic arrest were more manageable.

\section{Reconfiguration}

Depending on clinical trajectory, circuit reconfiguration should be anticipated during COVID-19 infection. With clinical improvement, cannulas can be consolidated to a single catheter in the neck to improve mobility and promote ambulation. For those initially supported by venoarterial ECMO, if there is cardiac recovery with persistent respiratory failure conversion to a VV-ECMO configuration can be performed. Patients initially supported by VV-ECMO may develop right ventricular or biventricular failure, in which cases a right ventricular assist device or an arterial cannula can be added to the circuit to transition to venoarterial ECMO support. In the ECMO COVID-19 Working Group experience, circuit reconfiguration was reported in $7 \%$ of cases. $^{8}$

\section{Circuit Management and Anticoagulation Therapy}

ECMO support times can be highly prolonged during COVID-19, reaching as far as several months. ${ }^{25}$ During these lengthy support times, it is critical to remain vigilant about cannula malposition, migration, erosion, and thrombosis. Volume management may improve low flows; however, in such cases radiograph and/or ultrasound-based imaging should be considered to confirm appropriate cannula tip positioning. If there is site erosion, an alternative vessel should be cannulated before onset of irreversible skin breakdown and infection.

Although severe COVID-19 infection is characterized and as a hyperinflammatory and prothrombotic state, current guidelines recommended standard anticoagulation with judicious blood product use. At current time, no single anticoagulation agent is recommended and use of unfractionated heparin is reported in most centers. Adequate anticoagulation must be confirmed to avoid thrombosis, especially during weaning stages with lower flow rates. ${ }^{25}$ Due to prolonged support times, circuit exchanges are not uncommon and were reported to occur in more than $10 \%$ of cases. $^{8}$

\section{Surge Case Capacity}

A tier-based surge capacity system has been proposed and can be adopted by centers to provide adequate ECMO support with appropriate case selection during the COVID-19 pandemic. ${ }^{25}$ Central to this system is establishment of a center's active case capacity load at baseline with contingency planning of thresholds for expanded and crises capacity levels. In addition, a daily reassessment of available resources, active cases, staffing and intensive care unit beds is essential for maintaining operations. If the system is within capacity, then ECMO can be offered with judicious patient selection based on usual criteria to COVID-19 
and non-COVID-19 cases. Once cases reach expanded capacity levels, then prioritization can be given to younger patients with single-organ failure. ECMO criteria can be restricted at near saturation of expanded capacity. If the system is saturated, ECMO, which requires significant staffing and allocation of supplies, may no longer be appropriate and resources should be concentrated to usual care. At crisis levels, it is important to consider termination of futile cases to increase capacity. This schema balances allocation of resources to saving lives of patients with severe respiratory failure while maintaining the quality of care of all patients.

\section{CONCLUSIONS}

Despite pessimism stemming from early reports, ECMO has served as an essential lifesaving modality during the COVID-19 pandemic. To further improve outcomes, it remains paramount to develop risk score models for optimal patient selection, create preemptive clinical protocols for close monitoring of tenuous patients to provide early ECMO, standardize cannulation procedures, determine optimal cannulation strategies, anticipate technical issues surrounding circuit management, perform daily assessments of case capacity, and develop diversion policies with a multidisciplinary team (Table 1$).{ }^{8}$ As the pandemic smolders, centers must reappraise local and regional pathways for providing ECMO coverage to care for the sickest patients with cardiopulmonary failure from COVID-19 and beyond.

\section{Conflict of Interest Statement}

Dr Silvestry is a consultant for Abbott Laboratories, Medtronic, Syncardia, and Abiomed outside of the submitted work. The other author reported no conflicts of interest.

The Journal policy requires editors and reviewers to disclose conflicts of interest and to decline handling or reviewing manuscripts for which they may have a conflict of interest. The editors and reviewers of this article have no conflicts of interest.

\section{References}

1. John Hopkins Resource Center. Available at: https://coronavirus.jhu.edu/map. html. Accessed September 25, 2021.

2. Bhatraju PK, Ghassemieh BJ, Nichols M, Kim R, Jerome KR, Nalla AK, et al. Covid-19 in critically ill patients in the Seattle region—case series. $N$ Engl $J$ Med. 2020;382:2012-22.

3. Potere N, Valeriani E, Candeloro M, Tana M, Porreca E, Abbate A. Acute complications and mortality in hospitalized patients with coronavirus disease 2019: a systematic review and meta-analysis. Crit Care. 2020;24:1-12.

4. Richardson S, Hirsch JS, Narasimhan M, Crawford JM, McGinn T, Davidson KW, et al. Presenting characteristics, comorbidities, and outcomes among 5700 patients hospitalized with COVID-19 in the New York City area. JAMA. 2020;323:2052-9.

5. Zeng Y, Cai Z, Xianyu Y, Yang BX, Song T, Yan Q. Prognosis when using extracorporeal membrane oxygenation (ECMO) for critically ill COVID-19 patients in China: a retrospective case series. Crit Care. 2020;24:1-3.

6. ELSO. COVID-19 dashboard. Available at: https://www.elso.org/COVID19. aspx. Accessed September 25, 2021.
7. Barbaro RP, MacLaren G, Boonstra PS, Iwashyna TJ, Slutsky AS, Fan E, et al. Extracorporeal membrane oxygenation support in COVID-19: an international cohort study of the Extracorporeal Life Support Organization registry. Lancet. 2020;396:1071-8.

8. Saeed O, Tatooles AJ, Farooq M, Schwartz G, Pham DT, Mustafa AK, et al. Characteristics and outcomes of patients with COVID-19 supported by extracorporeal membrane oxygenation: a retrospective multicenter study. J Thorac Cardiovasc Surg. May 18, 2021 [Epub ahead of print].

9. Lebreton G, Schmidt M, Ponnaiah M, Folliguet T, Para M, Guihaire J, et al. Extracorporeal membrane oxygenation network organisation and clinical outcomes during the COVID-19 pandemic in Greater Paris, France: a multicentre cohort study. Lancet Respir Med. 2021;9:851-62.

10. Rabie AA, Azzam MH, Al-Fares AA, Abdelbary A, Mufti HN, Hassan IF, et al. Implementation of new ECMO centers during the COVID-19 pandemic: experience and results from the Middle East and India. Intens Care Med. 2021;47:887-95.

11. Henry BM, Lippi G. Poor survival with extracorporeal membrane oxygenation in acute respiratory distress syndrome (ARDS) due to coronavirus disease 2019 (COVID-19): pooled analysis of early reports. J Crit Care. 2020;58:27.

12. Bartlett RH, Ogino MT, Brodie D, McMullan DM, Lorusso R, MacLaren G, et al. Initial ELSO guidance document: ECMO for COVID-19 patients with severe cardiopulmonary failure. ASAIO J. 2020;66:472.

13. Combes A, Hajage D, Capellier G, Demoule A, Lavoué S, Guervilly C, et al. Extracorporeal membrane oxygenation for severe acute respiratory distress syndrome. N Engl J Med. 2018;378:1965-75.

14. Odish MF, Yi C, Chicotka S, Genovese B, Golts E, Madani M, et al. Implementation and outcomes of a mobile extracorporeal membrane oxygenation (ECMO) program in the United States during the coronavirus disease 2019 (COVID-19) pandemic. J Cardiothorac Vasc Anesth. 2021;35:2869-74.

15. Zha L, Sobue T, Takeuchi T, Tanaka K, Katayama Y, Komukai S, et al. Characteristics and survival of intensive care unit patients with coronavirus disease in Osaka, Japan: a retrospective observational study. J Clin Med. 2021;10:2477.

16. Mustafa AK, Alexander PJ, Joshi DJ, Tabachnick DR, Cross CA, Pappas PS, et al. Extracorporeal membrane oxygenation for patients with COVID-19 in severe respiratory failure. JAMA Surg. 2020;155:990-2.

17. Zhang J, Merrick B, Correa GL, Camporota L, Retter A, Doyle A, et al. Venovenous extracorporeal membrane oxygenation in coronavirus disease 2019: a case series. ERJ Open Res. 2020;6:00463-2020.

18. Diaz RA, Graf J, Zambrano JM, Ruiz C, Espinoza JA, Bravo SI, et al. ECMO for COVID-19-associated severe ARDS in Chile: a nationwide incidence and cohort study. Am J Respir Crit Care Med. 2021;204:34-43.

19. Shih E, DiMaio JM, Squiers JJ, Banwait JK, Meyer DM, George TJ, et al. Venovenous extracorporeal membrane oxygenation for patients with refractory coronavirus disease 2019 (COVID-19): multicenter experience of referral hospitals in a large health care system. J Thorac Cardiovasc Surg. December 1, 2020 [Epub ahead of print].

20. Schmidt M, Hajage D, Lebreton G, Monsel A, Voiriot G, Levy D, et al. Extracorporeal membrane oxygenation for severe acute respiratory distress syndrome associated with COVID-19: a retrospective cohort study. Lancet Respir Med. 2020;8:1121-31.

21. Jacobs JP, Stammers AH, Louis JDS, Hayanga JA, Firstenberg MS, Mongero LB, et al. Multi-institutional analysis of 200 COVID-19 patients treated with ECMO: outcomes and trends. Ann Thorac Surg. 2021;21 [Epub ahead of print].

22. Ramanathan K, Shekar K, Ling RR, Barbaro RP, Wong SN, Tan CS, et al. Extracorporeal membrane oxygenation for COVID-19: a systematic review and metaanalysis. Crit Care. 2021;25:1-11.

23. Shaefi S, Brenner SK, Gupta S, O'Gara BP, Krajewski ML, Charytan DM, et al. Extracorporeal membrane oxygenation in patients with severe respiratory failure from COVID-19. Intens Care Med. 2021;47:208-21.

24. Cousin N, Bourel C, Carpentier D, Goutay J, Mugnier A, Labreuche J, et al. SARS-CoV-2 versus influenza-associated acute respiratory distress syndrome requiring veno-venous extracorporeal membrane oxygenation support. ASAIO J. 2021;67:125.

25. Badulak J, Antonini MV, Stead CM, Shekerdemian L, Raman L, Paden ML, et al. Extracorporeal membrane oxygenation for covid-19: updated 2021 guidelines from the Extracorporeal Life Support Organization. ASAIO J. 2021;67:485.

26. Pamukçu B. Inflammation and thrombosis in patients with COVID-19: a prothrombotic and inflammatory disease caused by SARS coronavirus-2. Anatol J Cardiol. 2020;24:224.

Key Words: COVID-19, ECMO, ARDS, mortality 